\title{
Effect of Stalk Desiccation on Sugarcane Red Rot
}

\author{
Zhi Yin and J. W. Hoy, Department of Plant Pathology and Crop Physiology, Louisiana Agricultural Experiment \\ Station, Louisiana State University Agricultural Center, Baton Rouge 70803
}

\begin{abstract}
Yin, Z., and Hoy, J. W. 1997. Effect of stalk desiccation on sugarcane red rot. Plant Dis. 81:1247-1250.

The effect of drought conditions at planting time on sugarcane red rot, caused by Colletotrichum falcatum, was evaluated in experiments conducted under controlled conditions and in the field. For experiments under controlled conditions, detached and topped mature stalks of five cultivars were inoculated with conidia of $C$. falcatum, then exposed to a 3-week desiccation treatment, followed by 3 weeks without desiccation, or maintained for 6 weeks without desiccation. Disease severity, assessed as the number of nodes beyond which rot symptoms extended, number of nodes rotted, internode rot severity, and a rot severity index, was increased in five cultivars by exposure to desiccation. However, response of individual cultivars varied for some disease traits assessed. In field experiments, C. falcatum inoculation alone did not reduce spring shoot populations for seven cultivars. The lowest shoot populations occurred in plantings of inoculated stalks exposed to desiccation. Some cultivars were adversely affected by desiccation alone. These results demonstrate that red rot severity can be increased by the occurrence of drought conditions during the initial growth processes of vegetatively propagated sugarcane stalks.
\end{abstract}

Red rot, caused by Colletotrichum falcatum Went, is an important disease of sugarcane (interspecific hybrids of Saccharum L.), which can cause severe losses in sucrose yield in many cane growing areas of the world $(1,6,8,14,18)$. Sugarcane is a vegetatively propagated crop. In Louisiana, red rot is primarily a disease that develops in planted stalks, rather than standing cane, that results in poor stand establishment $(1,8,20)$.

Sugarcane is grown at the northern limit of its cultivation range in Louisiana (9). Fall planting is needed to obtain adequate stalk maturity and sucrose yield the following growing season. The planting season extends from August through early October. To ensure an adequate shoot population the following spring, whole stalks are planted at a rate of approximately 4 to 8 stalks running in the planting furrow.

At the conclusion of the growing season, a plant cane crop is harvested, followed by first and second ratoon crops in subsequent years. After the fall harvest of the second ratoon crop, the cane stubble is plowed out during winter, and the land is fallowed until replanting. The fallow period greatly

Corresponding author: J. W. Hoy

E-mail: jhoy@unix1.sncc.lsu.edu

Approved for publication by the Director of the Louisiana Agricultural Experiment Station as manuscript number: 97-38-0024.

Accepted for publication 13 July 1997.

Publication no. D-1997-0829-02R

(C) 1997 The American Phytopathological Society reduces the possibility of soilborne inoculum of $C$. falcatum, since the fungus does not survive more than 6 months in soil or plant debris (13). Therefore, primary inoculum for stalk rot of planted stalks comes from infections of bud scales, nodal tissues, and leaf midribs that developed during the growing season $(3,4,7,11,12,20)$.

Red rot may develop in stalks after planting during a period extending through fall, winter, and early spring. Low shoot populations in plant cane do not occur annually, even with cultivars that are considered susceptible to red rot. Observational evidence suggests that the disease is favored by both excessive and deficient soil moisture, and by low temperatures $(8,14,15)$. These factors can adversely affect sugarcane growth, but have much less effect on the pathogen $(5,16,17,19)$. However, the possible relationships between different types of stress and sugarcane red rot severity are poorly understood. The objectives of this study were to investigate the effect of stalk desiccation on red rot under controlled conditions and in the field, and to evaluate the resistance to red rot of commercial sugarcane cultivars exposed to stress. A preliminary report has been published (21).

\section{MATERIALS AND METHODS}

Stalk desiccation experiments under controlled conditions. Experiments were conducted during fall 1993 and 1995. Five sugarcane cultivars, CP $65-357$, CP 70321, CP 72-370, LCP 82-89, and LCP 85384 , were used for the experiments. Intact, mature stalks without stalk borer or mechanical damage were cut by hand. Leaves and leaf sheaths were removed, and stalks were trimmed to contain 9 nodes. Stalks were surface-disinfested by dipping in an approximately $0.26 \% \mathrm{NaOCl}$ solution for 30 min before inoculation with $C$. falcatum. Inoculum preparation was as described previously (22). Twelve stalks of each cultivar were inoculated by introducing $100 \mu \mathrm{l}$ of a conidial suspension of $C$. falcatum into a 3.2-mm-diameter hole that was drilled into, but not through, the center internode of each stalk. The concentration of conidia was $3.8 \times 10^{6}$ spores $/ \mathrm{ml}$. Another 12 stalks of each cultivar were wounded by drilling a hole, but not inoculated. The inoculated and noninoculated stalks were each divided into two groups with 6 replicate stalks per cultivar. Groups of inoculated and noninoculated stalks of each cultivar were wrapped (inoculated and noninoculated groups separately) inside a perforated sheet of polyethylene with wet paper towels for 6 weeks. The other groups of each type were given a 3week desiccation treatment, then wrapped in plastic with wet towels and incubated for an additional 3 weeks. The desiccation treatment consisted of leaving the stalks exposed to ambient relative humidity (70 to $75 \%$ ) with a temperature range of 20 to $25^{\circ} \mathrm{C}$ in the storage room where the experiment was conducted.

To determine the effect of the desiccation treatment on stalk water loss, the weight was determined individually for 6 stalks of every cultivar in each treatment at the beginning of the experiments, after 3 weeks, and after 6 weeks at the conclusion of the experiments. Percent weight loss per stalk was determined by dividing stalk weight decrease at each date by initial stalk weight and multiplying by 100 . Weight losses then were compared among cultivars and treatments.

After 6 weeks, all stalks were split longitudinally and disease severity was assessed as: (i) the total number of nodes passed (NP) by internode rot symptoms in each direction from the inoculation point; (ii) the number of nodes in the assessed area with rot symptoms, and (iii) internode rot severity (IRS) in the inoculated internode and three internodes in either direction from the inoculation point. Internode rot severity was evaluated by visually rating the portion of tissue exhibiting red discoloration in each internode. Ratings were made on a scale of 1 to 6 , in which 1 $=10 \%$ or less, $2=1$ to $25 \%, 3=26$ to $50 \%, 4=51$ to $75 \%, 5=76$ to $90 \%$, and 6 $=$ greater than $90 \%$ of the internode tissue exhibiting red discoloration. Internode rot 
severity was then determined as an average of the 7 internodes assessed. An aggregate disease trait, rot severity index (RI), which combined the traits describing the extent of internode rotting and disease spread was calculated as RI $=\mathrm{NP} \times \mathrm{IRS}$.

Field experiments. The effect of stalk desiccation on red rot and sugarcane shoot populations produced during spring was evaluated in field experiments conducted at the St. Gabriel Branch Experiment Station of the Louisiana Agricultural Experiment Station at St. Gabriel, Louisiana. Seven commercial cultivars, CP 65-357, CP 70321, CP 72-370, CP 73-351, CP 74-383, LCP 82-89, and LCP 85-384, were planted during fall 1992 and 1993. Mature stalks without stalk borer or mechanical damage were hand-cut and topped so as to contain 9 nodes. After surface-disinfestation by dipping into an approximately $0.26 \%$ $\mathrm{NaOCl}$ solution for $30 \mathrm{~min}$, the stalks were divided into two groups. One group was inoculated with a conidial suspension of $C$. falcatum, and the other group was not in- oculated as described for the controlled conditions experiments. Half of the inoculated and noninoculated stalks was planted immediately. The other half was held in a storage room at ambient temperature and relative humidity for 3 weeks before planting. A split treatment arrangement with three replicates was used where the main plots were desiccation and no desiccation treatments. Inoculated and noninoculated stalks of each cultivar were planted in plots within main plots in a random design. Four and six stalks were planted per single row plot, $7.66 \mathrm{~m}$ in length, in 1992 and 1993, respectively. The number of shoots in each plot was counted the following spring. Percent reduction in shoot number was determined by dividing the cultivar shoot population means in the inoculation without desiccation, the desiccation without inoculation, and the inoculation with desiccation treatments by the corresponding cultivar mean from the noninoculated/no desiccation treatment.
Table 1. Effect of desiccation on number of nodes beyond which red rot symptoms were evident and a disease severity index in detached stalks of five cultivars maintained under controlled conditions

\begin{tabular}{lcl}
\hline & \multicolumn{2}{c}{ Disease trait $^{\mathbf{z}}$} \\
\cline { 2 - 3 } Treatment $^{\mathbf{y}}$ & Nodes passed (no.) & Index \\
\hline I/D & $4.1 \mathrm{a}$ & $2.20 \mathrm{a}$ \\
I/ND & $2.8 \mathrm{~b}$ & $1.09 \mathrm{~b}$ \\
NI/D & $0.3 \mathrm{c}$ & $0.03 \mathrm{c}$ \\
NI/ND & $0.1 \mathrm{c}$ & $0.01 \mathrm{c}$ \\
\hline
\end{tabular}

${ }^{\mathrm{y}} \mathrm{I} / \mathrm{D}=$ stalks inoculated with conidia of Colletotrichum falcatum then exposed to 3-week desiccation treatment; I/ND = inoculated stalks without desiccation; NI/D = noninoculated stalks with 3-week desiccation treatment; NI/ND = noninoculated stalks without desiccation.

${ }^{\mathrm{z}}$ Nodes passed (NP) refers to the number of nodes beyond which internode rot symptoms were evident in both directions from the inoculation point in the center internode. Index refers to a rot severity index $=\mathrm{NP} \times \mathrm{IRS}$ (the average percent discoloration of seven internodes). Values are means for five cultivars for two experiments combined. Means in a column followed by the same letter are not significantly different $(P=0.05)$ according to Fisher's least significant difference test.
Statistical analyses were conducted using the general linear model procedures of the Statistical Analysis System, Version 6.12 (SAS Institute Inc., Cary, NC). Data from the two experiments conducted under controlled conditions were combined and subjected to analysis of variance with year as a block. Because there were no significant cultivar by treatment interactions for the number of nodes passed and the disease index, the treatment effect for the two traits was evaluated with five cultivars combined. Data for experiments conducted under field conditions also were combined for analysis. Ratings data for internode rot severity were converted to the percentage midpoint for the appropriate interval and then transformed to arcsine square root values before statistical analysis. Data for stalk weight loss and percent shoot population reduction also were transformed to arcsine square root values before statistical analysis. Differences among treatment means were determined by using Fisher's least significant difference test at the $5 \%$ level of probability.

\section{RESULTS}

Effects of stalk desiccation on red rot under controlled conditions. Red rot development was greater in inoculated compared to noninoculated stalks with or without desiccation (Tables 1 to 3 ). Disease severity was always higher in inoculated stalks in 1995 than 1993 (results not shown). Disease severity in inoculated stalks, measured as the number of nodes passed and rot index, was increased by the 3-week desiccation treatment for the five cultivars combined (Table 1). Slight discoloration developed in the internodes in the middle of noninoculated stalks exposed to desiccation. However, symptom devel-

Table 2. Effect of desiccation on number of nodes rotted in detached stalks of five cultivars under controlled conditions

\begin{tabular}{lccccc}
\hline & \multicolumn{5}{c}{ Number of nodes rotted $^{\mathbf{z}}$} \\
\cline { 2 - 6 } Treatment $^{\mathbf{y}}$ & $\mathbf{C P 6 5 - 3 5 7}$ & CP70-321 & CP72-370 & LCP82-89 & LCP85-384 \\
\hline I/D & $3.3 \mathrm{a}$ & $2.3 \mathrm{a}$ & $3.3 \mathrm{a}$ & $2.6 \mathrm{a}$ & $2.6 \mathrm{a}$ \\
I/ND & $3.1 \mathrm{a}$ & $2.2 \mathrm{a}$ & $3.2 \mathrm{a}$ & $0.1 \mathrm{~b}$ & $2.8 \mathrm{~b}$ \\
NI/D & $0.1 \mathrm{~b}$ & $0.3 \mathrm{~b}$ & $0.1 \mathrm{~b}$ & $0.3 \mathrm{c}$ & $0.0 \mathrm{c}$ \\
NI/ND & $0.0 \mathrm{~b}$ & $0.0 \mathrm{~b}$ & $0.0 \mathrm{~b}$ & 0.0 & $\mathrm{~b}$ \\
\hline
\end{tabular}

${ }^{\mathrm{y}} \mathrm{I} / \mathrm{D}=$ stalks inoculated with conidia of Colletotrichum falcatum then exposed to 3-week desiccation treatment; $\mathrm{I} / \mathrm{ND}=$ inoculated stalks without desiccation; NI/D = noninoculated stalks with 3-week desiccation treatment; NI/ND = noninoculated stalks without desiccation.

${ }^{z}$ Values are means for two experiments combined. Means in a column followed by the same letter are not significantly different $(P=0.05)$ according to Fisher's least significant difference test.

Table 3. Effect of desiccation on internode rot severity of detached stalks in five cultivars under controlled conditions

\begin{tabular}{|c|c|c|c|c|c|}
\hline \multirow[b]{2}{*}{ Treatment $^{\mathbf{y}}$} & \multicolumn{5}{|c|}{ Internode rot severity $(\%)^{\mathrm{z}}$} \\
\hline & CP65-357 & CP70-321 & CP72-370 & LCP82-89 & LCP85-384 \\
\hline I/D & $42 \mathrm{a}$ & $50 \mathrm{a}$ & $38 \mathrm{a}$ & $50 \mathrm{a}$ & $54 \mathrm{a}$ \\
\hline I/ND & $37 \mathrm{a}$ & $29 \mathrm{~b}$ & $38 \mathrm{a}$ & $30 \mathrm{~b}$ & $37 \mathrm{~b}$ \\
\hline NI/D & $10 \mathrm{~b}$ & $12 \mathrm{c}$ & $8 \mathrm{~b}$ & $9 \mathrm{c}$ & $2 c$ \\
\hline NI/ND & $3 c$ & $8 c$ & $7 \mathrm{~b}$ & $1 \mathrm{~d}$ & $2 \mathrm{c}$ \\
\hline
\end{tabular}

${ }^{\mathrm{y}} \mathrm{I} / \mathrm{D}=$ stalks inoculated with conidia of Colletotrichum falcatum then exposed to 3-week desiccation treatment; $\mathrm{I} / \mathrm{ND}=$ inoculated stalks without desiccation; NI/D = noninoculated stalks with 3-week desiccation treatment; NI/ND = noninoculated stalks without desiccation.

${ }^{\mathrm{z}}$ Internode rot severity was the average percent discoloration of seven internodes. Values are means for two experiments combined. Means in a column followed by the same letter are not significantly different $(P=0.05)$ according to Fisher's least significant difference test. 
opment was minimal in noninoculated stalks. The number of nodes rotted and internode rot severity varied among the five cultivars. Desiccation only increased the number of nodes rotted for one cultivar, LCP 85-384 (Table 2). Internode rot severity was increased for CP 70-321, LCP 8289, and LCP 85-384 (Table 3). Desiccation also increased internode discoloration for noninoculated stalks of CP 65-357 and LCP 82-89 (Table 3). An increase in disease severity resulting from desiccation was observed for 2 of 4 disease traits for CP 65-357 and CP 72-370, 3 of 4 traits for CP 70-321 and LCP 82-89, and 4 of 4 traits for LCP 85-384.

Stalk weight loss ranged from 14 to $17 \%$ among cultivars after the 3 weeks of desiccation. Further stalk weight decreases occurred during the 3 weeks after the desiccation treatment. The additional losses were not significant; however, they affected the relationship among cultivars. After the 3-week treatment, CP 65-357 (16.9\%) experienced a greater weight loss than CP $72-370$ (13.8\%), while the other cultivars were intermediate $(P=0.05)$. After an additional 3 weeks with no desiccation, LCP $85-384$ (17.7\%) had a greater stalk weight loss than CP 72-370 (15.2\%). Stalk weight losses among the five cultivars ranged from 0.8 to $2.9 \%$ after 6 weeks without desiccation. There was a significant year effect in the combined analysis, with the initial stalk weights and losses for all the cultivars being greater in 1995 than in 1993.

Stalk desiccation and red rot effects on spring sugarcane shoot populations in field experiments. Inoculation with $C$. falcatum in the absence of stalk desiccation did not result in a reduction in spring shoot population for seven cultivars (Table 4). Cultivars varied in their response to desiccation and the combination of inoculation with $C$. falcatum and desiccation. Spring shoot population was adversely affected by desiccation without inoculation for $\mathrm{CP} 70$ 321, CP 74-383, and LCP 82-89. The effects of desiccation alone and desiccation with inoculation were comparable in $\mathrm{CP}$ 74-383, LCP 82-89, and LCP85-384. Spring shoot populations were lower in the inoculated/desiccation than in the noninoculated/without desiccation treatment for six of the seven cultivars.
Inoculation with $C$. falcatum without desiccation resulted in spring shoot population reductions ranging from 0 to $19 \%$ for the seven cultivars, but the reductions were not different among the tested cultivars (Table 5). Desiccation alone resulted in 38 to $76 \%$ shoot reductions for the sensitive cultivars, CP 70-321, CP 74-383, and LCP 82-89; however, only CP 74-383 exhibited a greater reduction than CP 65-357 and CP 73-351 (Table 5). C. falcatum inoculation with desiccation resulted in spring shoot population reductions ranging from 51 to $84 \%$ among seven cultivars. The shoot population reductions for CP 73351 and LCP 85-384 were less than that observed for LCP 82-89. Desiccation and inoculation had a synergistic effect on spring shoot population reduction in six of the seven cultivars.

\section{DISCUSSION}

Red rot severity, assessed as the number of nodes beyond which rot symptoms extended, number of nodes rotted, internode rot severity, and a rot severity index, was increased in stalks of five sugarcane cultivars by stalk desiccation in experiments conducted under controlled conditions. Field experiment results demonstrated that stalk desiccation occurring during the fall at the beginning of bud germination, and growth of vegetatively propagated stalks can increase the detrimental effect of red rot on shoot population the following spring. Without desiccation, disease did not adversely affect spring shoot popula- tions of seven cultivars in two seasons. Stalk desiccation alone resulted in shoot population reductions in some cultivars. However, the lowest shoot population always occurred in plots where inoculated, desiccated stalks were planted. The desiccation treatment was intended to induce drought stress in treated stalks. Red rot incidence was observed to increase when standing cane was exposed to drought stress (10). However, this is the first demonstration by experimental means that the severity of red rot of planted sugarcane could be increased by drought stress.

Stalk rot symptoms developed in sugarcane cultivars inoculated with $C$. falcatum and held under controlled conditions, but reductions in spring shoot populations in plots planted with inoculated stalks were not observed in the two field experiments. Stalk rot severity assessed in inoculated, planted stalks dug up from the field after varying intervals of time is similar to the severity of symptoms observed in inoculated stalks held under controlled conditions (unpublished data). The field experiment results suggest that red rot development in planted stalks does not always adversely affect stand establishment. There are conflicting reports about the potential spread of disease from infected stalk tissues into germinating buds and young shoots. Edgerton (8) and Singh (12) reported that the fungus did not infect young shoots from diseased stalks. However, several reports $(4,7)$ described the

Table 5. Shoot population reductions in seven cultivars caused by Colletotrichum falcatum inoculation, desiccation, or both

\begin{tabular}{lccl}
\hline & \multicolumn{3}{c}{ Percent shoot reduction $^{\mathbf{z}}$} \\
\cline { 2 - 4 } Cultivar & Inoculation & Desiccation & Both \\
\hline CP65-357 & $7 \mathrm{a}$ & $7 \mathrm{c}$ & $70 \mathrm{abc}$ \\
CP70-321 & $12 \mathrm{a}$ & $38 \mathrm{abc}$ & $73 \mathrm{abc}$ \\
CP72-370 & $19 \mathrm{a}$ & $16 \mathrm{bc}$ & $71 \mathrm{abc}$ \\
CP73-351 & $0 \mathrm{a}$ & $8 \mathrm{c}$ & $59 \mathrm{bc}$ \\
CP74-383 & $10 \mathrm{a}$ & $76 \mathrm{a}$ & $82 \mathrm{ab}$ \\
LCP82-89 & $8 \mathrm{a}$ & $55 \mathrm{ab}$ & $84 \mathrm{a}$ \\
LCP85-384 & $18 \mathrm{a}$ & $13 \mathrm{bc}$ & $51 \mathrm{c}$ \\
\hline
\end{tabular}

${ }^{\mathrm{z}}$ Percent shoot reduction was determined by dividing the cultivar shoot population mean reductions in the inoculated treatment without desiccation, the desiccation without inoculation treatment, and the inoculation with desiccation treatment (both) by the corresponding cultivar mean from the noninoculated/no desiccation treatment. Values are means for shoot population reduction in each of two experiments with the experiments considered as blocks. Means followed by different letters within a column were different at $P=0.05$.

Table 4. Effect of stalk desiccation and red rot on spring shoot populations of seven sugarcane cultivars

\begin{tabular}{|c|c|c|c|c|c|c|c|}
\hline \multirow[b]{2}{*}{ Treatment $^{\mathbf{y}}$} & \multicolumn{7}{|c|}{ Shoot population per plot $^{\mathrm{z}}$} \\
\hline & CP65-357 & CP70-321 & CP72-370 & CP73-351 & CP74-383 & LCP82-89 & LCP85-384 \\
\hline NI/ND & $23 \mathrm{a}$ & $35 \mathrm{a}$ & $35 \mathrm{a}$ & $28 \mathrm{a}$ & $28 \mathrm{a}$ & $41 \mathrm{a}$ & $33 \mathrm{ab}$ \\
\hline I/ND & $21 \mathrm{a}$ & $32 \mathrm{a}$ & $26 \mathrm{a}$ & $31 \mathrm{a}$ & $24 \mathrm{a}$ & $47 \mathrm{a}$ & $41 \mathrm{a}$ \\
\hline NI/D & $23 \mathrm{a}$ & $22 \mathrm{~b}$ & $28 \mathrm{a}$ & $27 \mathrm{a}$ & $9 \mathrm{~b}$ & $22 \mathrm{~b}$ & $27 \mathrm{ab}$ \\
\hline I/D & $9 \mathrm{~b}$ & $11 \mathrm{c}$ & $15 \mathrm{~b}$ & $11 \mathrm{~b}$ & $8 \mathrm{~b}$ & $9 \mathrm{~b}$ & $19 \mathrm{~b}$ \\
\hline
\end{tabular}

${ }^{\text {y }} \mathrm{NI} / \mathrm{ND}=$ noninoculated stalks without 3-week desiccation treatment; I/ND = stalks inoculated with conidia of Colletotrichum falcatum without desiccation; NI/D = noninoculated stalks exposed to 3-week desiccation treatment; I/D = inoculated stalks exposed to 3-week desiccation treatment.

${ }^{\mathrm{z}}$ Treatment means were presented for seven cultivars individually from two experiments combined. Means followed by different letters within a column were different at $P=0.05$ according to Fisher's least significant difference test. 
spread of C. falcatum from diseased stalks into emerging shoots. Desiccation apparently can increase disease symptom severity in sugarcane stalks. Environmental stress conditions also may determine the extent to which red rot affects bud germination and shoot development, survival, and regrowth in the spring.

Visible symptoms of desiccation, including stalk shrinkage that results in longitudinal wrinkling of the rind and internal internode discoloration, were evident in the ends of stalks. In preliminary experiments, conidia were introduced into internodes at the ends of stalks. Desiccation treatment appeared to increase disease severity, but the discoloration associated with desiccation interfered with disease assessment. The effects of stalk desiccation on disease severity could be greater in the ends of stalks, but disease was increased even in the center portions of inoculated, desiccated stalks.

In summary, desiccation increased disease severity in stalks of some cultivars more than others. However, in field experiments, red rot and desiccation together had a synergistic effect on spring shoot population reductions for all cultivars, except for one cultivar that was very sensitive to desiccation. The results have implications for research efforts to control red rot and on-farm management of the disease. Breeding and selection for host plant resistance is the most important control measure for red rot $(1,2,8,14,22)$. All of the cultivars currently grown in Louisiana are susceptible to red rot (22). An evaluation of the differential effects of desiccation on resistance among different sugarcane genotypes could improve the development of resistant cultivars. Timing farm cultural practices to avoid or minimize drought stress at and after planting should reduce red rot severity and improve plant cane stands.

\section{ACKNOWLEDGMENTS}

We thank Lori Grelen for technical assistance.

\section{LITERATURE CITED}

1. Abbott, E. V. 1938. Red rot of sugarcane. U. S. Dep. Agric. Tech. Bull. 641.

2. Abbott, E. V., Zummo, N., and Tippet, R. L. 1967. Methods of testing sugarcane varieties for disease resistance at the U. S. Sugar Cane Field Station, Houma, Louisiana. Proc. Int. Soc. Sugar-Cane Technol. 12:1138-1141.

3. Agnihotri, V. P., and Budhrajia, T. R. 1974. Pathogenic potentialities of midrib isolates of Colletotrichum falcatum in inciting stalk rot of sugarcane. Sugarcane Pathol. Newsl. 11:19-21.

4. Agnihotri, V. P., Budhrajia, T. R., and Singh, K. 1979. Role of diseased sett and soil and the annual recurrence of red rot in sugarcane. Int. Sugar J. 82:263-265.

5. Ahmed, H. U., and Divinagracia, G. G. 1974. Growth and sporulation of Colletotrichum falcatum at different temperatures, $\mathrm{pH}$, and light conditions. Phillip. Agric. 57:379-382.

6. Bourne, B. A. 1953. Studies on sugarcane red rot in the Florida Everglades. Proc. Int. Soc. Sugar-Cane Technol. 8:915-924.

7. Chona, B. L. 1950. Studies on the diseases of sugarcane in India. III. Sources and modes of red rot infection. Indian J. Agric. Sci. 20:363385.

8. Edgerton, C. W. 1911. The red rot of sugarcane. La. Agric. Exp. Sta. Bull. 133.

9. Matherne, R. J., Breaux, R. D., and Millhollon, R. W. 1977. Culture of sugarcane for sugar production in the Mississippi delta. U. S. Dep. Agric. Handb. No. 417.

10. Olufolaji, D. B. 1989. The effect of water stress on red rot in sugar cane. Sugar Cane, Autumn 1989 Supplement: 16-17.
11. Sandhu, S. S., Mehan, V. K., and Singh, K. 1974. Role of leaf mid-rib lesions in epidemiology of red rot caused by Colletotrichum falcatum Went. in the Punjab. Indian Sugar 24:391-395.

12. Singh, G. R. 1968. Red rot infection and its development in young sugarcane plants. Proc. Int. Soc. Sugar-Cane Technol. 13:1243-1250.

13. Singh, K., Budhraja, T. R., and Agnihotri, V. P. 1977. Survival of Colletotrichum falcatum in soil, its portals of entry and role of inoculum density in causing infection. Int. Sugar J. 79:43-44

14. Singh, K., and Singh, R. H. 1988. Red rot. Pages 169-188 in: Diseases of Sugarcane Major Diseases. C. Ricaud, B. T. Egan, A. G. Gillaspie, Jr., and C. G. Hughes, eds. Elsevier, New York.

15. Singh, N. 1985. Effect of amendment on red rot development in sugarcane. Indian Phytopathol. 38:382-384.

16. Singh, N., and Lal, R. J. 1987. Viability of red rot pathogen under waterlogged conditions. Plant Dis. Rep. 2:104-105.

17. Singh, N., Lal, S., and Singh, R. P. 1985. Behavior of Colletotrichum falcatum under stress condition. Indian Phytopathol. 38:544545.

18. Singh, O., and Waraitch, K. S. 1981. Effect of wilt and red rot induced disease stress on quality deterioration of sugarcane. Sugarcane Pathol. Newsl. 27:25-29.

19. Singh, P. 1973. Effect of light, temperature, and substrate during spore formation on the germinability of conidia of Colletotrichum falcatum. Physiol. Plant 29:194-197.

20. Steib, R. J., and Chilton, S. J. P. 1951. Infection of sugarcane stalk by red rot fungus Phy salospora tucumanensis Speg. Phytopathology 41:522-528.

21. Yin, Z., Hoy, J. W., and Milligan, S. B. 1994 Heritability of resistance to red rot and the effect of environmental stress on disease severity. (Abstr.) Phytopathology 84:1148.

22. Yin, Z., Hoy, J. W., and Milligan, S. B. 1996. Evaluation and heritability of resistance to sugarcane red rot. Phytopathology 86:662667. 